\title{
Antimicrobial Activity of Essential Oil and Major Constituents of Salvia chloroleuca
}

\author{
Morteza Yousefzadi ${ }^{a}$,*, Ali Sonboli ${ }^{\mathrm{b}}$, Samad Nejad Ebrahimic, \\ and Seid Hasan Hashemi ${ }^{\mathrm{d}}$ \\ a Department of Marine Biology, Faculty of Sciences, Hormozgan University, Bandar Abbas, \\ Iran. E-mail: morteza110110@gmail.com \\ b Department of Biology, Medicinal Plants and Drugs Research Institute, \\ Shahid Beheshti University, Evin, 1983963113, Tehran, Iran \\ c Department of Phytochemistry, Medicinal Plants and Drugs Research Institute, \\ Shahid Beheshti University, Evin, Tehran, Iran \\ d Department of Biology, Faculty of Science, Zabol University, Zabol, Iran \\ * Author for correspondence and reprint requests
}

Z. Naturforsch. 63c, 337-340 (2008); received August 27/October 16, 2007

The aerial parts of Salvia chloroleuca were collected at full flowering stage at Shahrestanak (Tehran province of Iran). The essential oil was isolated by hydrodistillation and analyzed by combination of capillary GC and GC-MS. Thirty-four components were identified, representing $98.5 \%$ of the total oil. $\beta$-Pinene $(10.6 \%), \alpha$-pinene $(9.0 \%), \beta$-caryophyllene $(9.0 \%)$, 1,8 -cineole $(9.0 \%)$ and carvacrol $(7.9 \%)$ were the main components. The in vitro antimicrobial activity of the essential oil of S. chloroleuca was studied against seven Gram-positive and Gram-negative bacteria (Bacillus subtilis, Enterococcus faecalis, Staphylococcus aureus, S. epidermidis, Escherichia coli, Pseudomonas aeruginosa and Klebsiella pneumoniae) and three fungi (Candida albicans, Saccharomyces cerevisiae and Aspergillus niger); the disc diffusion method and MIC values indicated that the oil exhibited moderate to high antimicrobial activity.

Key words: Salvia chloroleuca, Antimicrobial Activity, Essential Oil

\section{Introduction}

Essential oils obtained from many plants have recently gained popularity and scientific interest. Many plants have been used for different purposes, such as food, drugs and perfumery. Researchers have been interested in biologically active compounds isolated from plant species for the elimination of pathogenic microorganisms because of the resistance that microorganisms have built against antibiotics (Tepe et al., 2005).

Salvia, the largest genus of Lamiaceae, includes about 900 species, widespread throughout the world. This genus is represented in Iranian flora by 58 species, 17 of which are endemic (Mozaffarian, 1996). Some of these species are used as medicinal, aromatic and ornamental plants. Salvia officinalis is one of the most widespread species and, since ancient times, has been used in the treatment of various disorders, such as tuberculosis and psoriasis. It has shown strong antibacterial and antifungal activities (Rustaiyan et al., 1999). Other members of this genus have been used in folk medicine around the world for their antibacterial (Ulubelen et al., 1997) and antitumour (Topcu, 2006) activities and as flavouring agent in perfumery and cosmetics (Tzakou et al., 2001).

A literature survey revealed that no chemical composition and biological studies had been performed on the essential oil of S. chloroleuca. The aim of our study was to evaluate the chemical composition of S. chloroleuca essential oil and its antimicrobial activity.

\section{Material and Methods}

\section{Plant material}

The aerial parts of $S$. chloroleuca Rech. f. \& Aell. were collected at Shahrestanak, Tehran province of Iran, at an altitude of $2300 \mathrm{~m}$. A voucher specimen (AS-85106) has been deposited at the herbarium of Ecology and Systematic Department, Research Institute of Applied Science, Shahid Beheshti University, Tehran, Iran. 


\section{Isolation of the essential oil}

Air-dried aerial parts of the plants $(250 \mathrm{~g})$ were hydrodistilled for $4 \mathrm{~h}$ using a Clevenger type apparatus. The resulting essential oil was dried over anhydrous sodium sulfate and stored at $4{ }^{\circ} \mathrm{C}$ until analyzed and tested.

\section{$G C$ and $G C-M S$ analyses}

GC-FID analysis of the oil was conducted using a Thermoquest-Finnigan instrument equipped with a DB-5 fused silica column $(60 \mathrm{~m} \times 0.25 \mathrm{~mm}$ i.d., film thickness $0.25 \mu \mathrm{m}$ ). Nitrogen was used as the carrier gas at the constant flow rate of $1.1 \mathrm{ml} /$ min. The split ratio was $1 / 50$. The oven temperature was raised from $60{ }^{\circ} \mathrm{C}$ to $250^{\circ} \mathrm{C}$ at a rate of $5{ }^{\circ} \mathrm{C} / \mathrm{min}$. The injector and detector (FID) temperatures were kept at $250^{\circ} \mathrm{C}$ and $280{ }^{\circ} \mathrm{C}$, respectively. GC-MS analysis was carried out on a Thermoquest-Finnigan Trace GC-MS instrument equipped with the same column and temperature programming as mentioned for $\mathrm{GC}$ analysis. Transfer line temperature was $250^{\circ} \mathrm{C}$. Helium was used as the carrier gas at a flow rate of $1.1 \mathrm{ml} / \mathrm{min}$ with a split ratio equal to $1 / 50$.

The constituents of the essential oil were identified by calculation of the retention indices of $n$-alkanes $\left(\mathrm{C}_{6}-\mathrm{C}_{24}\right)$ under temperature-programmed conditions on a DB-5 column under the same conditions. Identification of individual compounds was made by comparison of their mass spectra with those of the internal reference mass spectra library (Wiley 7.0) or of authentic compounds and confirmed by comparison of their retention indices with those of authentic compounds or with those reported in the literature (Adams, 2001). Semiquantitative data was obtained from FID area percentages without the use of correction factors.

\section{Antimicrobial activity}

Ten microbial strains were used which included: Bacillus subtilis (ATCC 465), Enterococcus faecalis (ATCC 29737), Staphylococcus aureus (ATCC 25923), Staphylococcus epidermidis (ATCC 12228), Escherichia coli (ATCC 25922), Klebsiella pneumoniae (ATCC 10031), Pseudomonas aeruginosa (ATCC 85327), Aspergillus niger (ATCC 16404), Candida albicans (ATCC 10231) and Saccharomyces cerevisiae (ATCC 9763).

The antimicrobial activity of the essential oil and its main components was determined by the disc diffusion method (Baron and Finegold, 1990).
Briefly, $0.1 \mathrm{ml}$ of a suspension of the test microorganism $\left(10^{8}\right.$ cells $\left./ \mathrm{ml}\right)$ was spread on Mueller-Hinton Agar plates for bacterium and Sabouraud Dextrose Agar for the fungi. Sterile $6 \mathrm{~mm}$ discs, each containing $10 \mu \mathrm{l}$ of essential oil, were placed on the microbial lawns. Discs containing $10 \mu \mathrm{l}$ of carvacrol, $\beta$-caryophyllene, 1,8-cineole, $\alpha$-pinene and $\beta$-pinene were used to study the antimicrobial activity of the major oil components. The plates were incubated at $37^{\circ} \mathrm{C}$ for $24 \mathrm{~h}$ for the bacteria

Table I. Composition of the essential oil of Salvia chloroleuca.

\begin{tabular}{|c|c|c|}
\hline Compound & $\mathrm{RI}^{\mathrm{a}}$ & $\%$ of the oil \\
\hline Tricyclene & 926 & 1.4 \\
\hline$\alpha$-Pinene & 936 & 9.0 \\
\hline Camphene & 949 & 3.2 \\
\hline Sabinene & 970 & 5.0 \\
\hline$\beta$-Pinene & 978 & 10.6 \\
\hline Myrcene & 982 & 0.9 \\
\hline$\varrho$-Cymene & 1015 & 3.7 \\
\hline 1,8-Cineole & 1025 & 9.0 \\
\hline$(E)$ - $\beta$-Ocimene & 1037 & 0.7 \\
\hline$\gamma$-Terpinene & 1052 & 2.7 \\
\hline Terpinolene & 1081 & 0.2 \\
\hline Linalool & 1084 & 1.2 \\
\hline trans-Pinocarveol & 1128 & 0.8 \\
\hline trans-Verbenol & 1132 & 0.5 \\
\hline Borneol & 1155 & 2.7 \\
\hline Terpinen-4-ol & 1166 & 2.0 \\
\hline Myrtenal & 1175 & 1.1 \\
\hline Myrtenol & 1182 & 0.6 \\
\hline Thymol & 1265 & 0.3 \\
\hline Carvacrol & 1281 & 7.9 \\
\hline Tridecane & 1285 & 1.0 \\
\hline Eugenol & 1322 & 0.7 \\
\hline$\alpha$-Copaene & 1385 & 0.7 \\
\hline Tetradecane & 1395 & 4.9 \\
\hline$\beta$-Caryophyllene & 1430 & 9.0 \\
\hline$\alpha$-Humulene & 1460 & 0.6 \\
\hline Germacrene D & 1485 & 6.4 \\
\hline Bicyclogermacrene & 1499 & 1.5 \\
\hline Spathulenol & 1573 & 3.3 \\
\hline Caryophyllene oxide & 1581 & 3.8 \\
\hline Epoxy allo-aromadendrene & 1619 & 1.1 \\
\hline$\beta$-Eudesmol & 1645 & 1.0 \\
\hline$\alpha$-Bisabolene oxide & 1661 & 0.5 \\
\hline Platambin & 1842 & 0.5 \\
\hline Monoterpene hydrocarbons & & 37.4 \\
\hline Oxygenated monoterpenes & & 26.1 \\
\hline Sesquiterpene hydrocarbons & & 18.2 \\
\hline Oxygenated sesquiterpenes & & 9.7 \\
\hline Others & & 7.1 \\
\hline Total & & 98.5 \\
\hline
\end{tabular}

Compounds are listed in the order of their elution from a DB-1 column.

a $\mathrm{RI}$, retention index relative to $n$-alkanes $\left(\mathrm{C}_{6}-\mathrm{C}_{24}\right)$. 
and $30{ }^{\circ} \mathrm{C}$ for $48 \mathrm{~h}$ for the fungi. The diameters of the zones of inhibition were measured and reported in mm. Triplicate tests were carried out for each sample.

MIC (minimum inhibitory concentration) values were determined by a broth microdilution assay (NCCLS, 1997, 1999). Serial two-fold dilutions of the essential oil were made in Mueller-Hinton Broth containing $0.5 \%$ Tween 80 for bacteria and Sabouraud Dextrose Broth with $0.5 \%$ Tween 80 for fungi in 96-well microtiter plates. Fresh microbial suspensions prepared from overnight grown cultures in the same media were added to give a final concentration of $5 \cdot 10^{5}$ organisms $/ \mathrm{ml}$. Controls of medium with microorganisms or the essential oil alone were included. The microplates were incubated at $37^{\circ} \mathrm{C}$ for $24 \mathrm{~h}$ for the bacteria and $30^{\circ} \mathrm{C}$ for $48 \mathrm{~h}$ for the fungi. The first dilution with no microbial growth was recorded as MIC.

\section{Results and Discussion}

The essential oil composition of $S$. chloroleuca is presented in Table I, where all compounds are listed in the order of their elution from a DB-1 column. The oil yield was $0.3 \%(\mathrm{w} / \mathrm{w})$ based on the dry weight of the plant. Thirty-four components were identified, representing $98.5 \%$ of the total oil. Monoterpene hydrocarbons were the major compounds group and constituted $37.4 \%$ of the oil. Among them, $\beta$-pinene (10.6\%), and $\alpha$-pinene $(9.0 \%)$ were identified as the main compounds. Oxygenated monoterpenes comprised $26.1 \%$ of the oil; 1,8-cineole (9.0\%) and carvacrol (7.9\%) were determined as their principal components. $\beta$ Caryophyllene $(9.0 \%)$ and germacrene D $(6.4 \%)$ were characterized as the main constituents among the sesquiterpene hydrocarbons.

The essential oil of S. chloroleuca was tested against four Gram-positive and three Gram-negative bacteria, as well as three fungi. The result of the bioassay (Table II) showed that the oil exhibited moderate to high antimicrobial activity against all the fungi and bacteria tested, except for two microorganisms, Pseudomonas aeruginosa and Aspergillus niger. The most sensitive microorganisms were Bacillus subtilis, Staphylococcus epidermidis and S. aureus with inhibition zones of 21, 19, $15 \mathrm{~mm}$ and MIC values of $3.75,3.75$ and $7.5 \mathrm{mg} /$ $\mathrm{ml}$, respectively. Five microbial strains, Escherichia coli, Enterococcus faecalis, Klebsiella pneumoniae, Saccharomyces cerevisiae and Candida albicans, were found to be less sensitive to the oil.

Table III shows the antimicrobial activity of five major components of the oil. Among them the antimicrobial activity of carvacrol was superior compared to the other components. 1,8-Cineole exhibited high to moderate antibacterial activity against the test bacteria, while its antifungal properties were moderate. $\alpha$-Pinene and $\beta$-caryophyllene showed moderate antibacterial activity, except for $K$. pneumoniae and P. aeruginosa, with inhibition zones ranging from 10 to 15 and 9 to $15 \mathrm{~mm}$, respectively. No antifungal activity was determined for these two components. $\beta$-Pinene showed no

Table II. Antimicrobial activity of the essential oil of Salvia chloroleuca.

\begin{tabular}{|c|c|c|c|c|c|c|c|c|}
\hline \multirow[t]{2}{*}{ Microorganism } & \multicolumn{2}{|c|}{ S. chloroleuca } & \multicolumn{2}{|c|}{$\begin{array}{l}\text { Tetracycline } \\
(30 \mu \mathrm{g} / \text { disc })\end{array}$} & \multicolumn{2}{|c|}{$\begin{array}{l}\text { Gentamicin } \\
(10 \mu \mathrm{g} / \text { disc })\end{array}$} & \multicolumn{2}{|c|}{$\begin{array}{l}\text { Nystatine } \\
(30 \mu \mathrm{g} / \text { disc })\end{array}$} \\
\hline & $\mathrm{IZ}^{\mathrm{a}}$ & $\mathrm{MIC}^{\mathrm{b}}$ & $\mathrm{IZ}$ & MIC & $\mathrm{IZ}$ & MIC & $\mathrm{IZ}$ & MIC \\
\hline B. subtilis & $21 \pm 0.2$ & 3.75 & $21 \pm 0.8$ & 3.2 & - & $\mathrm{nt}$ & $\mathrm{nt}$ & $\mathrm{nt}$ \\
\hline E. faecalis & $13 \pm 0.4$ & 15 & $9 \pm 0.4$ & 6.4 & - & $\mathrm{nt}$ & $\mathrm{nt}$ & $\mathrm{nt}$ \\
\hline S. aureus & $15 \pm 0.3$ & 7.5 & $20 \pm 0.4$ & 3.2 & - & $\mathrm{nt}$ & $\mathrm{nt}$ & $\mathrm{nt}$ \\
\hline S. epidermidis & $19 \pm 0.8$ & 3.75 & $34 \pm 0.8$ & 1.6 & - & $\mathrm{nt}$ & $\mathrm{nt}$ & $\mathrm{nt}$ \\
\hline E. coli & $14 \pm 0.2$ & 15 & - & $\mathrm{nt}$ & $23 \pm 0.8$ & 3.2 & $\mathrm{nt}$ & $\mathrm{nt}$ \\
\hline K. pneumoniae & $12 \pm 0.4$ & 15 & - & $\mathrm{nt}$ & $20 \pm 0.8$ & 3.2 & $\mathrm{nt}$ & $\mathrm{nt}$ \\
\hline P. aeruginosa & - & $\mathrm{nt}$ & - & $\mathrm{nt}$ & $12 \pm 0.4$ & 6.4 & $\mathrm{nt}$ & $\mathrm{nt}$ \\
\hline A. niger & - & $\mathrm{nt}$ & $\mathrm{nt}$ & $\mathrm{nt}$ & $\mathrm{nt}$ & $\mathrm{nt}$ & $16 \pm 0.4$ & 6.4 \\
\hline C. albicans & $10 \pm 0.4$ & $>10$ & $\mathrm{nt}$ & $\mathrm{nt}$ & $\mathrm{nt}$ & $\mathrm{nt}$ & $18 \pm 0.4$ & 3.2 \\
\hline S. cerevisiae & $11 \pm 0.2$ & $>10$ & $\mathrm{nt}$ & $\mathrm{nt}$ & $\mathrm{nt}$ & $\mathrm{nt}$ & $18 \pm 0.8$ & 1.6 \\
\hline
\end{tabular}

Values are given as means \pm standard deviation.

a Zone of inhibition (in $\mathrm{mm})$ includes diameter of the disc $(6 \mathrm{~mm})$.

b Minimum inhibitory concentration in $\mathrm{mg} / \mathrm{ml}$. -, Inactive; 7-13, moderately active; $>14$, highly active; nt, not tested. 


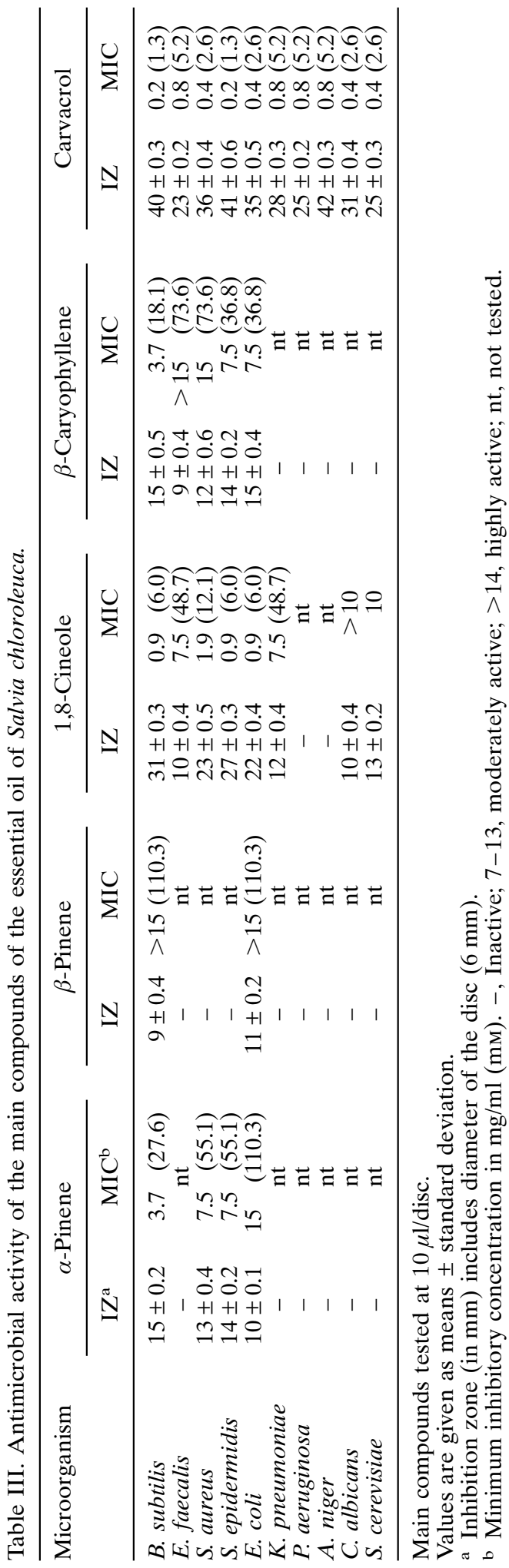

considerable antimicrobial activity towards the test microorganisms.

Adams R. P. (2001), Identification of Essential Oils Components by Gas Chromatography/Quadrupole Mass Spectroscopy. Allured Publishing Co., Carol Stream, IL, USA.

Baron E. J. and Finegold S. M. (1990), Methods for testing antimicrobial effectiveness. In: Diagnostic Microbiology (Stephanie M., ed.). Mosboy, Baltimore, MD, pp. $171-194$.

Mozaffarian V. (1996), A Dictionary of Iranian Plant Names. Farhang Moaser, Tehran, Iran.

National Committee for Clinical Laboratory Standards (NCCLS) (1997), Performance standards for antimicrobial disk susceptibility test, $6^{\text {th }}$ ed. Approved Standard. M100-A6. Wayne, PA, USA.

National Committee for Clinical Laboratory Standard (NCCLS) (1999), Performance standards for antimicrobial susceptibility testing. $9^{\text {th }}$ International Supplement. M100-S9. Wayne, PA, USA.

Rustaiyan A., Masoudi S., Monfared A., and Komeilizadeh H. (1999), Volatile constituents of three Salvia species grown wild in Iran. Flavour Fragr. J. 14, 276-278.

Tepe B., Daferera D., Sokmen A., Sokmen M., and Polissiou M. (2005), Antimicrobial and antioxidant activities of the essential oil and various extracts of Salvia tomontosa. Food Chem. 90, 333-340.

Topcu G. (2006), Bioactive triterpenoids from Salvia species. J. Nat. Prod. 69, 482-487.

Tzakou O., Pitarokili B., Chinou L. B., and Harvala C. (2001), Composition and antimicrobial activity of the essential oil of Salvia vingens. Planta Med. 67, 81-83.

Ulubelen A., Tan N., and Topcu G. (1997), Terpenoid from Salvia candidissima subsp. candidissima. Phytochemistry 45, 1221-1223. 